January 2003

\title{
Aids, orphans, and development in Sub-Saharan Africa: A review of the dilemma of public health and development
}

Joe Lugalla

Follow this and additional works at: http://ecommons.aku.edu/eastafrica_ied

Part of the Gender and Sexuality Commons, Immune System Diseases Commons, and the Social Welfare Commons

\section{Recommended Citation}

Lugalla, J. (2003). Aids, orphans, and development in Sub-Saharan Africa: A review of the dilemma of public health and development. Journal of Developing Societies, 19(1), 26-46.

Available at: http://ecommons.aku.edu/eastafrica_ied/86 


\title{
AIDS, ORPHANS, AND DEVELOPMENT IN SUB-SAHARAN AFRICA: A REVIEW OF THE DILEMMA OF PUBLIC HEALTH AND DEVELOPMENT
}

\author{
Joe L.P Lugalla*
}

\begin{abstract}
HIV/AIDS is having devastating consequences on families, young children, and other vulnerable social groups. In this paper, I review the impact of HIVIAIDS on families and development in sub-Saharan Africa. I begin by showing the magnitude of the problem and the factors that have led to rapid spread of HIV/AIDS in this sub-continent. I discuss gender inequality, poverty, social inequality, and globalization, and show how these facilitate the rapid spread of the epidemic. I show how AIDS is creating a mass of orphans on the one hand, and how it is impacting development and creating new public health contradictions on the other. By orphans I mean all those children who have lost either a mother or father or both parents due to AIDS. I argue that AIDS is destroying families and communities and is also manufacturing a great number of orphaned children who are powerless and vulnerable. In order to solve this problem, I suggest the adoption of appropriate, pragmatic, and realistic short- and long-term strategies of dealing with the problem. I conclude by suggesting that the long-term strategy aimed at reducing the number of orphaned children will involve the adoption of appropriate strategies that seek to control HIV/AIDS once and for all.
\end{abstract}

\section{Introduction}

With AIDS, we are confronting an epidemic that began with a whisper only two decades ago and now roars like thunder around the globe. Everyday 5,000 people throughout the world are infected with HIV. AIDS is the fourth biggest killer in the world and in

* Department of Anthropology, University of New Hampshire, 316 Huddleston Hall, Durham, NH, 03824,USA, (jlpl@cisunix.unh.edu or Lugalla@hot mail.com).

(C) de Sitter Publications 2003

$J D S$ 19(1):26-46 
sub-Saharan Africa it is the leading cause of death. Since the epidemic began, more than 60 million people (worldwide) have been infected with the virus (UNAIDS/WHO 2001:1). Recent data show that about 42 million people globally are now living with HIV. Five million people were newly infected in 2002 and 3.1 million people died of AIDS in the same year (UNAIDS/WHO 2002:2).

In many parts of the developing world, the majority of those affected are young adults, with young women being especially vulnerable. About one-third of those currently living with AIDS are between the ages of 15 to 24; most of them do not know that they carry the virus (UNAIDS/WHO 2001:1).

In this paper, I review the nature of the AIDS epidemic in sub-Saharan Africa. I discuss briefly its impact, focusing particularly on the problem of AIDS orphans and how this problem causes new challenges in public health and development discourse in this subcontinent. Finally, I suggest ways that countries in sub-Saharan Africa can adopt in order to deal with these new public health development challenges.

\section{The Magnitude of the Problem}

Worldwide, sub-Saharan Africa remains the region most severely affected by the AIDS epidemic. Of the 42 million people estimated to be living with AIDS by December 2002 sub-Saharan Africa accounted for 29.4 million or 70 percent (UNAIDS/WHO 2002:6). Of the 5 million new HIV infections in 2002 alone, the share from this sub-continent was 3.5 million or 70 percent (p.6). Of the 3.1 million people who died of AIDS in 2002, 2.4 million or 77 percent were from this sub-continent (p.6). Most of those who are infected are women, young people, and more particularly women in their teens. The rate of infection in this social group is twice or three times that of young men of the same age. In 2001, an estimated 6 to 11 percent of young women aged 15 to 24 were living with HIV/AIDS compared to 3 to 6 percent of young men (UNAIDS/ WHO 2002:19). The factors behind this are obvious. Unlike men, women and girls do not have equal access to resources of wealth, power, and prestige like education, employment, capital, credit, and 
land. They also lack inheritance rights in the case of death of their husbands, fathers or other relatives. This condition puts women in a vulnerable situation of being poorer than their male counterparts. On the other hand, poverty forces women to depend on men for their own survival. Dependence and subordination make it very difficult for women and girls to negotiate sexual encounters, practice safe sex, and deny sexual relationships that are high risk and can lead to infection. At the same time, lack of access to education and information means that women and girls are more likely to be ignorant about sexual and reproductive health and HIV/AIDS than their male counterparts. Due to these factors, HIV prevalence rates have risen to alarming levels in many parts of the sub-continent. For example, in four Southern African countries, national adult HIV prevalence has risen higher than thought possible, exceeding 30 percent in several areas: Botswana (38.8 percent), Lesotho (31 percent), Swaziland (33.4 percent), and Zimbabwe (33.7 percent) (UNAIDS/ WHO 2002:17). As the report by United Nations and the World Health Organization suggests, the food crisis faced by Swaziland, Lesotho, and Zimbabwe are linked to the toll of their longstanding HIV/AIDS epidemic; especially on the lives of young productive adults (p.17). In five West African countries (Burkina Faso, Cameroon, Ivory Coast, Niger, and Togo), national adult prevalence rates had already passed 5 percent in 2000 (UNAIDS/WHO 2001:14). While countries like Nigeria have been forced to increase their budget spending on HIV/AIDS, others, like Tanzania and Uganda have formed specific commissions that can deal with AIDS. For example, the establishment of the Tanzania Commission on AIDS (TACAIDS) and Uganda AIDS Commission are cases in point. Although the AIDS situation is at present very severe in Southern Africa and rising slowly in West Africa, there is positive news from East Africa where the epidemic was severe in the first decade of the epidemic. Existing data show that there is a downward arc in the prevalence rates in Uganda. HIV prevalence in pregnant women in urban areas has fallen for eight years in a row, from a high of 29.5 percent in 1992 to 11.25 percent in 2000 (UNAIDS/WHO 2001:15). Focusing heavily on information, education and communication, and decentralized programs that reach down to the village 
level, Uganda's efforts have also boosted condom use across the country. In the Masindi and Pallisa districts, condom use with casual partners in 1997 to 2000 rose from 43 percent and 31 percent respectively to 51 and 53 percent (p.15). In the capital of Kampala, almost 98 percent of sex workers surveyed in the year 2000 said they used a condom the last time they had sex (p.15).

In Tanzania, similar positive trends have been recorded in Kagera region by the Kagera AIDS Research Project Team (of which the author is a member). The findings show that the overall age-adjusted HIV-1 prevalence in the high-prevalence urban area of Bukoba declined from 24.2 percent in 1987 to 18.2 percent in 1993 and later to 13.3 percent in 1996. (Kwesigabo 2001:26). In the medium prevalence area of Muleba, overall age-adjusted prevalence declined from 10 percent in 1987 to 6.8 percent in 1996 and later to 4.3 percent in 1999 (p.26). In the low prevalence area of Karagwe, the prevalence declined from 4.5 percent in 1987 to 2.6 percent in 1999 (p.26). In all three areas, the most significant decline was consistently observed among females in the age group of 12 to 24 years (p.26). The HIV-1 incidence in urban Bukoba declined from 47.5 to 9.1 per 1000 PYAR in 1989 and 1996 respectively, while it decreased in Muleba from 8.2 to 3.9 in 1989 and 2000 respectively (p.29). Although studies aimed at explaining these trends are currently on going, there is a strong indication that a behavioral change is taking place. Kwesigabo (2001:30) preliminary findings show that there is a significant rise in condom use from 22.6 percent to 30.3 percent between 1993 to 1996 regardless of the type of sexual partner. Like Uganda, it is evident in Tanzania too that information, education, and communication, and the agony of AIDS have contributed much to these declining trends. These stories that signify hope have also been recorded in other countries. A study in Zambia shows urban men and women reporting less sexual activity, fewer multiple partners, and more consistent use of condoms. Probably, this explains why HIV prevalence rates are declining, especially among young women aged 15 to 24 (UNAIDS/WHO 2001:14). Recent reports show that in South Africa for pregnant women under 20, HIV prevalence rates fell to 15.4 percent in 2001 from 21 percent in 1998 (UNAIDS/WHO 2002:17). In Addis Ababa in 
Ethiopia, infection levels among women aged 15 to 24 attending antenatal clinics dropped from 24.2 percent in 1995 to 15.1 percent in 2001 (pp.17-18).

The experiences of Uganda, Kagera in Tanzania, Zambia, and Ethiopia underscore the fact that even epidemics like AIDS can be arrested at any point in time if people are willing to do so and if there is both the political will and commitment on the part of the government. These experiences also confirm that fighting against HIV/AIDS has to involve interventions that are multifaceted.

A variety of studies carried out by both sociologists and anthropologists, insist the importance of understanding AIDS in a social context. Through the work of anthropologists like Brooke Grundfest Schoepf and Paul Farmer, we are now becoming increasingly aware that epidemics do not happen by chance or in a vacuum but rather in a social context. Disease epidemics are social processes. Schoepf (2001:336) argues that political economy, social relations, and culture shape the spread of infections agents. AIDS has struck with particular severity in communities struggling under the burden of poverty, inequality, economic crisis, and war. She argues that many people who know about the danger of sexually transmitted diseases, especially many girls and women, cannot avoid becoming infected because they cannot control the relations of power that put their lives at risk (p.336). It is also becoming evident that HIV risk in Africa is not confined to any special "risk group" or category of persons. AIDS is neither a disease of poor women engaged in commercial sex or long-distance truck drivers. Although men and women in these occupations are at extremely high risk, they do not form bounded groups (Schoepf 1996:155).

It is also important to acknowledge the global interconnections in the rapid transmission of HIV/AIDS in sub-Saharan Africa. Studies have shown how global or macro level structures and processes have destroyed lives at micro level, and how this has led to the spread of HIV (Farmer 1992, 1996; Lugalla et al. 1999; Schoepf 2001). The uncontrolled process of globalization and the adoption of structural adjustments and their free-market shock therapy of lowering trade barriers, eliminating subsidies, raising interest rates, and devaluation of currencies have driven up the cost of 
living. This has ripped holes in already shuttered economies and has helped in killing small farmers and small businesses most of which have always functioned as safety nets for the survival of the poor (Lugalla et al. 1999). Many people have lost their land to transnational corporations that pay people low wages. Devaluation has increased inflation and the cost of living. Reduction in government expenditure had led to retrenchment, increasing unemployment, diminishing access to education and health. Coupled with deepening poverty, this has brought mass social dislocations, hunger, diseases, and untold suffering. In some countries, the majority poor have been structurally adjusted "to death." All this has increased the risks to HIV infection. In showing how this happens in real life, Farmer (1992) shows how the construction of a hydroelectric dam funded by USAID drove peasants from their land, which increased poverty, migration, and the risks of AIDS. ${ }^{1}$ A similar process in Ghana drove women from uprooted, landless families to seek earning opportunities in Ivory Coast where the only work they found was as prostitutes, and many contracted HIV. ${ }^{2}$ During my recent visit to Iringa, Tanzania, I noted how deepening rural poverty forced many young rural girls to migrate to Dar-es-Salaam to search for work as domestic servants. A follow up in Dar-es-Salaam revealed that most of these immigrants ended up working as maids in the entertainment industry (hotels, pubs, and bars) and some become "Changu-Doas" (a Swahili term for young urban prostitutes). As a consequence of such processes, it is believed that the number of these girls sent back home either sick or dead due to AIDS has been alarming during the last few years. ${ }^{3}$

\section{AIDS and Orphans}

One of the severe negative impacts of HIV/AIDS in sub-Saharan Africa is the rapid increase of children orphaned by AIDS. In countries hardest hit by AIDS, staggering numbers of children have been orphaned. Overall, AIDS is increasing the number of vulnerable, malnourished, poorly socialized, and uneducated young people, which in turn heightens the prospect of social instability (UNAIDS/UNICEF/USAID 2002:9). The number of African chil- 
dren who have lost either the mother or father or both parents due to AIDS was 12.1 million by the end of 2000 (UNAIDS/WHO 2001:7). This figure is predicted to double over the next decade (p.7). In 1995, one out of every 10 children was parentless in Uganda (The Boston Globe, November 23, 1995). In Zambia, a 1996 survey in a heavily affected area revealed that almost 75 percent of families included one orphan (Hunter and Williamson 2000:5). These orphans are particularly vulnerable to the epidemic. Often they are living with young aunts, uncles, or siblings who are too impoverished to provide adequate care (Hunter and Williamson 2000:5). In most cases it is the women, young and old (many of whom are also suffering from AIDS or other infectious diseases), who become guardians and caretakers of orphaned children and other ailing relatives or spouses. The story of Naomi from Ileje Tanzania illustrates this point.

I was born in 1983 in Malangali village as a third child of my mother who was married to our father as a third wife. Our father rarely spent time with us. He used to move from one house to the other, and rarely supported us financially. He built for us a small muddy house that was thatched with a grass roof. We had a very small farm in which we produced maize and beans. In order to supplement income, my mother used to make a local brew called 'Kimpumu' and sold it at the village local club every day. I began assisting her in this business when I was in the first grade. I used to sell this beer every evening when I came back from school. I had no time to study and sometimes I had difficulties finishing the school homework assignments. But I had no alternative, except to do it because it was from the sales of this beer that my mother paid our school fees and also bought us school uniforms. My sister who used to work with us in this business became pregnant when she was sixteen. She had to drop out of school. After delivering a baby boy, she left the boy with my mother and went to Vwawa in Mbozi to work as a bar attendant. The problems intensified a year before I graduated from primary school when my mother died. My 
younger brother and I, together with the son of my sister had to move to our grandmother (the mother of my mother). The grandmother was very old and was taking care of four other grandchildren of her son (my uncle) who had died three years ago. Life was difficult. We hardly had enough food, and in most cases we ate once a day. When I finished my primary education in 1998, I decided to migrate to Isongole in order to look for work. As you can see now, I work here as a bar attendant. My salary is Tshs. 5000 per month. This amount of money is not enough because I am renting a room for Tshs 3000 a month. Right now I have a boyfriend who is assisting me in paying the house rent. As you can note, I am now pregnant. I do not know how I will take care of the child and work at the same time. (Lugalla and Barongo 2000:79)

This story is a clear illustration of how orphaned children, particularly girls, become vulnerable to high-risk sexual behavior. In this case, poverty and lack of support for Naomi has forced her to immigrate and to enter into a risky sexual union that makes her vulnerable to HIV. Many orphaned children experience these problems. Lack of basic needs becomes a norm and chronic malnutrition becomes widespread. Life becomes difficult, tempting, too painful, and too short. Since most of the caretakers are women, orphaned children are significantly more disadvantaged than children in twoparent households. This is precisely because women have less access to property, employment, and other resources of power. A recent study in Tanzania showed that there has been a rise in the proportion of households headed by women; from 18 percent in 19911992 to 23 percent in 2000-2001 (HBS 2002:5). The findings show a small rise in the proportion of households headed by persons who are over 65 years old. The study found that women have less access to education than their male counterparts and that there is a close relationship between education, income, and poverty (HBS 2002:825). This means that female-headed households are more likely to be poorer than male-headed households in Tanzania.

Besides problems associated with poverty, orphaned children experience a variety of psychological problems. They are 
denied the basic closeness of family life, parental love, attention, and affection. As parents and other family members become ill, children take on greater responsibility for income generation, food production, and care of family members (UNAIDS/UNICEF/ USAID 2002:9). Many of them are likely to drop out from school. A review by UNICEF on the effects of orphaning on schooling and child labor in $20 \mathrm{sub}$-Saharan African countries revealed that in all countries, children aged 15 to 24 who had lost one or both parents were less likely to be in school and more likely to be working more than 40 hours a week (UNAIDS/UNICEF/USAID 2002:10). A survey of 646 orphaned and 1,239 non-orphaned children in Kenya found that 52 percent of orphaned children were not in school, while only 2 percent of non-orphaned children were not enrolled (p.10). According to UNAIDS/WHO (2001:6), in Swaziland, school enrollment is reported to have fallen by 36 percent due to AIDS. Sometimes due to poverty, orphans may be coerced into the sex trade, which predisposes them to HIV, and once infected it is difficult for them to access good health care. Cases of orphans being abused by foster parents, adults or guardians are not hard to find. In some cases, orphans and widows can loose property and inheritance rights, a situation that can enhance their poverty. This increases the risk of psychosocial distress that can hinder their ability to cope.

The rapid increase of orphans has had devastating consequences on local communities. As the number of children in difficult circumstances rise, some communities have been forced to establish social support structures in order to offer assistance. In some areas where extended-family support structures have collapsed and community support is lacking, some children have migrated to urban areas where they live as street children; surviving by begging, pick-pocketing, prostitution, and street vending. Lugalla and Kibassa $(2002: 12 ; 2003)$ have noted a close association between increasing numbers of orphans and the rise of street children in East Africa.

\section{AIDS and Development}

The impact of HIV/AIDS on children and development of subSaharan Africa is complex and has deleterious social and economic 
costs that are high and long term. The growing number of orphaned children and infants who are born with HIV/AIDS is putting the future development of the continent in serious doubt. In most African countries experiencing severe economic difficulties, AIDS is bringing in new socioeconomic challenges. According to a joint program on HIV/AIDS by UNAIDS and WHO (2001:5), the epidemic is threatening human welfare, developmental progress, and stability at an unprecedented scale. The program provides ample evidence that steep drops in life expectancy are now showing up in many severely affected countries. Botswana, Malawi, Mozambique, and Swaziland now have a life expectancy of less than 40 years. Without AIDS, the average life expectancy in this sub-continent would be approximately 47 years. In South Africa, the program found that the average life expectancy is estimated at 47 years instead of 66 years.

The AIDS epidemic has had very severe negative consequences on economic growth, income, and poverty. Development and stability is being threatened. UNAIDS/WHO (2001:5) project has evidence indicating that the annual per capita growth in half the countries of Sub-Saharan Africa is falling by .5 to 1.2 percent. Moreover, as a direct result of AIDS worldwide, heavily affected countries could lose more than 20 percent of GDP by 2020 . Employment organizations and governments have incurred enormous expenses for training new personnel to replace those who have died. At the same time they spend a lot of money for paying benefits, insurance, social security, and funeral costs to those who die. Working hours are also lost due to absenteeism and illness. According to the UNAIDS/WHO report (2001:5), a survey of 15 firms in Ethiopia has shown that over a five-year period, 53 percent of all illnesses among staff were AIDS-related. In Malawi and Zambia, five to six fold increases in health worker illness and death rates have reduced personnel, increased stress levels and workload for remaining employees (p.6). In 1999 alone, an estimated 860,000 children lost their teachers due to AIDS in sub-Saharan Africa. In Central Africa Republic, AIDS was the cause of 85 percent of the 300 teachers who died in 2000 (UNAIDS/WHO 2001:6). In Zambia, teacher deaths caused by AIDS are equivalent to about half 
the total number of new teachers the country manages to train annually (p.6). In some countries there are so many deaths that the custom for funerals now is to have them all on weekends so that mourners can attend. Due to the many deaths, funeral services are now quick and sermons are short and brief. A similar trend has been observed in Lusaka in Zambia and Nairobi in Kenya. In Tanzania, deaths are so many and frequent to the extent that they have entirely changed the culture of death and mourning. Traditionally, for instance, the Matanga was a period of mourning (usually lasting 3 to 4 days) whereby relatives, friends, and community members would sleep, sing, and eat together at the deceased's home. Matanga have now changed to Tanga-Ndugu, where only very close relatives are allowed to stay and sleep at the deceased home. For the other mourners, the ceremony ends after the funeral/burial.

Although almost everyone in this sub-continent is becoming vulnerable to the economic impact of HIV/AIDS, the poor suffer most. In the micro economy, the situation is worse. The income lost from the death of the breadwinner is devastating. Often children drop out of school because they cannot afford the fees. Instead, they act as caretakers or work to supplement household incomes. According to the UNAIDS and WHO joint program (2001:5), onequarter of households in Botswana, where adult HIV prevalence is over 35 percent, can expect to lose an income earner within the next 10 years. They find that the per capita household income for the poorest quarter of households is expected to fall by 13 percent, while every income earner in this class will absorb four or more dependants as a result of HIV/AIDS. This is a matter of great concern, considering that in most countries the economic hardships of the past two decades have left 75 percent of the continent's people surviving on less than U.S. \$2 a day.

Due to illness and deaths, the agricultural sector is suffering dearly, fuelling other crises, most notably famine and hunger, particularly in southern Africa. A recent WHO report (November 2002; online source) argues that "AIDS is combining with other factorsincluding droughts, floods and in some cases short-sighted national and international policies - to cause a steady fall in agricultural production and to cut deep into household income." The report indi- 
cates that 7 million agricultural workers in 25 African countries have died of AIDS since 1985. In 2001 alone, AIDS killed nearly 500,000 people in the six predominantly agricultural countries threatened with famine, most of whom were in their productive prime. AIDS-related deaths in farm households caused crop output to drop by as much as 60 percent. A study in central Malawi has shown that about 70 percent of the households surveyed suffered labor losses due to sickness. About 20 percent of rural families in Burkina Faso are estimated to have reduced their agricultural work or even abandoned their farms because of AIDS. The prospect of widespread food shortages and hunger in this sub-continent is real (WHO Report November 2002; online source). In Kenya, for example, the death of a household head was associated with a 68 percent reduction in the net value of farming output, largely because labor losses had forced farmers to cultivate much smaller areas of land (UNAIDS/WHO 2002:31-32). In Zimbabwe, another study found that if a household suffered an AIDS-related death the output in smallholder farms shrank by 29 percent for cattle, 49 percent for vegetables, and 61 percent for maize (p.32). As rural poverty intensifies and income dwindles, both men and women are forced to emigrate in search of greener pastures. In most cases, those who emigrate do it alone without being accompanied by their sexual partners - a situation that can lead to multi-partnered sexual behavior. For city or town immigrants who are women, since employment opportunities are in short supply, being involved in the sex trade can become the only alternative. At the same time, the impact of AIDS in agriculture has to consider that the majority of people infected with HIV tend to be women and girls, who are responsible for 50 to 80 percent of food production, other farm work, and domestic related activities. Therefore their sickness leads to devastating consequences in production and reproduction in sub-Saharan Africa.

Given this situation, there is no doubt that AIDS is posing a threat to the future development of the sub-continent. The AIDS epidemic is occurring at the time of economic insecurity. In addition, although economic opportunities have widened with globalization, the opportunities have not been distributed equally. We also see that poverty is increasing and traditional safety nets are collapsing. 
It is believed that the ability of the states to ensure law and order might be compromised as the epidemic, poverty, corruption, and lack of accountability and responsibility looms large in institutions whose task is to maintain peace, human rights, and social justice. If not arrested, this trend can lead to social unrest and political instability.

\section{Where Do We Go From Here?}

It is clear that HIV/AIDS is destroying communities and families and is affecting the development of many nations in Africa. Longterm solutions to controlling the further spread of HIV/AIDS should adopt poverty alleviation strategies that are realistic and pragmatic. Simply promoting the use of condoms is not an effective strategy on its own.

We have seen that primary intervention policies targeting specific social groups are not effective. For instance, women with multiple partners do not consider themselves as prostitutes. Nor do they consider themselves to be prostitutes when they are struggling to support their families in a period of economic crisis (Schoepf 1996:166). There is no doubt that information, communication, and education (IEC) increases people's knowledge, but hardly leads to significant behavioral change. IEC can work well if combined with culturally appropriate community-based interventions. These strategies assist people to address wider issues related to health, gender, poverty, household economics, and sexual relationships (Schoepf 1996:166). This can also enable men to understand the advantage of changing their traditional attitudes towards women.

Linking the macro-level political economy to micro-level ethnography demonstrates that although gender relations are sometimes subject to negotiation, women's struggles to improve their condition takes place in circumstances not of their own making (Schoepf 1996:153). In this situation, health campaigns and other educational programs are bound to fail if women are not empowered socially and economically. The government as well as NGOs should support income-generating projects that are initiated and controlled by women. This includes the accessibility to micro financing. 
However, women can benefit from such strategies only if they are aware of them and are conscious about their situation. Creating awareness among women can be achieved successfully through the following ways. First, girls have to have equal access to all levels of education without discrimination. Second, there is a need to establish informal women's associations that can impart emancipative consciousness among women. It is important for official term-policies to support these social movements because they help to strengthen processes of emancipation. The establishment of the Tanzania Association of Women Lawyers in Tanzania (TAWLA), The Tanzania Media Women Association (TAMWA), and The Tanzania Gender Networking Program (TGNP) are steps in the right direction. Greater educational opportunities for women create an enabling environment within which these processes of emancipation can take place. Education is important for a number of reasons. Many studies reveal that the amount of education attained by girls and women is an important determinant of children's health. A study of 45 developing countries found out that the average mortality rate of children under 5 years was 144 per 1000 live births when their mothers had no education, 106 per 1000 when they have primary education, and 68 per 1000 when they have some secondary education (World Bank 1998-99). The World Bank has also shown that as knowledge spreads, infant mortality rates fall.

Intervention programs must also continue to target adolescents. Health education and information about safe sex has to be encouraged in schools and institutions of higher learning. African governments must acknowledge the following facts: First, that as individual partner choice gradually replaces arranged marriages, and age at first marriage rises, most adolescents tend to practice premarital sexual relationships. Second, new social norms and values associated with modernity, westernization, and economic motivation are increasingly encouraging adolescents to be sexually active before marriage. The present strategy of denying teaching young people about condoms and, at the same time, blaming individuals for spreading AIDS, is counterproductive. The foundation of success in fighting AIDS must include a combination of massive and comprehensive public-health campaigns aimed at changing 
risky sexual behaviors and pragmatic strategies of alleviating poverty. Rather than simply distributing condoms or telling people to abstain. People's attitudes towards condom use and safe practices can change only in a secure economic and social environment.

\section{How to Assist Orphans}

The following recommendations are offered to help support orphaned children. Unfortunately, many official social-welfare systems, run by government, in Africa are inefficient and lack adequate funds to establish orphanages, introduce foster parenthood with support from government or introduce a sophisticated system that can allow families to adopt orphaned children. This means that in the near future, African countries will continue to rely on the social support system provided by the extended family, which is already under severe economic pressure. In order to maintain the remaining structure, official policies will have to consider appropriate ways of enhancing the capacities of families to deal with their socioeconomic problems. Existing poverty alleviation and other strategies must be considered in conjunction with access to credit facilities, land, and official protection. Once this is in place, official policies can encourage foster parenthood and promote ways of supporting adoption families. It is also important to create a legal infrastructure that can protect such children from losing their inheritance rights to the property of their parents.

As of today, it is only nongovernmental organizations that have been engaged in assisting orphans in retaining and regaining their inheritance rights. Governments need to enact special laws that can address this issue as well. It is important to make sure that children are aware of their rights and institutions that can protect or defend them. These messages might be followed with a legal regime that protects the rights of children and women to inherit property. The legal regime must also target irresponsible men who run away from providing child support for their families. The effective legal regime must also be accompanied by legal education so that orphans as well as widows know their rights as well and how to either defend or fight for them. Most orphans neither know what 
abuse is and what is not. Even when they are severely abused they do not know where they can report for assistance. The ordeal expressed below by an orphaned girl and boy from Ileje Tanzania is a clear illustration of this dilemma.

As children, we are always harassed and suffer much from both physical and verbal abuse. To whom can we report? It is the adults who treat us in this way. Even if you report to the Police, these too do not trust what the children say. The other thing is that if you report these problems to the Police, you might risk being beaten again by the people you have reported. (Lugalla and Barongo 2000:49)

An orphaned boy lamented his feelings in the following way:

It is common in Ileje for children to be beaten by adults. We are beaten at home, we are beaten at school and sometimes if you do something wrong in streets you also risk being beaten by community members. I do not know how these problems can be resolved. (Lugalla and Barongo 2000:49)

These examples illustrate how difficult it is to establish community intervention. The point can be that communities can assist to develop self-independence, which in the long run benefits the community as a whole. However, a hurdle to establishing community intervention involves building trust and reporting mechanisms, accountability and security. Children need basic necessities for survival before they can benefit from education, health information on safe sex, condom provision, and vocational training. These children in particular need to be encouraged and allowed to participate in decisions that affect their lives. Present policies that harass street children are more likely to harm than assist them. Long-term policies must aim at addressing essential causes that create street children rather than considering street children as being responsible for their own situation.

Although the orphaned children are already victims of HIV/AIDS, many of them go on to live with relatives or families 
that are either suffering from AIDS or are nursing an AIDS patient. Families with meager financial resources struggle to support both victims. Programs that focus on assisting families that care for HIV/AIDS patients in their homes will also strengthen their ability to care for orphans. Orphans can survive well if state or community intervention is in place. The two can be of great help if resources at the local level are mobilized and strengthened. For example, village governments can be instrumental in making sure that deceased property like land is protected and finally passed over to the widows and orphaned children. African local communities have traditions of assisting each other or working cooperatively. There are also different informal systems of reciprocity and procedures whereby individuals assist each other in farm work on a rotational basis. The cases of "Mtharagambo" and "Mgove" between the Pare and Hehe of Tanzania respectively, point to the fact that the ideology of assistance and cooperation is not a new concept in Africa. This resource can be taped and used in designing a system of organizing cooperative childcare.

\section{Conclusion}

The increasing number of children orphaned by AIDS is a development and public health challenge that many African countries will have to grapple with in the coming years. How these countries will deal with children who are also infected with HIV is a mystery given the fact that the countries are poor and their health-care systems are dilapidated and notoriously under funded. There is no doubt that it is very unlikely that African countries alone, without support from the outside global world, will be able to address this problem adequately. Outside support will certainly be needed, but should this be the case, this support should only come in order to supplement locally initiatives that have been put in place by the African countries themselves in order to confront this challenge. Outside aid can only be effective if it only supports locally created initiatives.

In order to confront this challenge, the strategies must be multifaceted, multidimensional, short and long term. As for short- 
term strategies, a variety of social-work related programs would be needed in order to assist the orphaned children who are already there. Besides creating orphanages, policies must aim at strengthening communities and family support networks so that they can be able to support orphaned children. The government will have to establish procedures that support the adoption of children (i.e., foster parenthood.) The families that are willing to do that should be supported morally, materially, and by the legal regime. It will also be crucial for governments to expand education and health infrastructure and to make arrangements that can enable orphaned children to access these services freely. It is also important for government to initiate non-formal education coupled with vocational and entrepreneurship training in order to train and impart skills to the children who cannot join the formal education system.

In terms of long-term strategies, the problem of increased AIDS orphans can be controlled if the long-term strategies to confront HIV/AIDS are successful. Governments ought to continue with rigorous efforts of fighting AIDS by expanding interventions that are down to earth, realistic, and sensitive to local conditions. These should include massive education and health campaigns so that people understand what AIDS is, how it spreads, and finally how to protect oneself from it. More centers for voluntary counseling and testing have to be opened, and people must be encouraged to test in order to know their HIV status. These strategies can work well if: society's stigmas against AIDS disappear; if those who are infected are supported and encouraged to live positively with HIV/AIDS; and if antiretroviral drugs are supplied to those who have developed AIDS in order to prolong their life.

Both short- and long-term strategies can be implemented and are likely to bring positive results. However, their implementation and success requires political commitment from governments that are accountable and are willing to put the needs and voices of their people first.

\section{NOTES}

1 Quoted from Brooke G. Schoepf, "International AIDS Research in Anthropology: Taking a Critical Perspective on 
the Crises." Annual Review of Anthropology 2001(30):343. The original information is from Paul E. Farmer's AIDS and Accusation: Haiti and the Geography of Blame, Berkeley: University of California Press, 1992.

2 This information has been quoted from Brooke G. Schoepf, cited above. However, the original information appeared in R.W. Porter's “AIDS in Ghana: Priorities and Policies." See in D. Feldman, ed., Global AIDS Policy, Westport, Connecticut: Bergin and Garvey, 1994, p.245.

3 This observation is also confirmed by The Guardian Newspaper of Tanzania of November 29, 2002 which wrote the following message: "A large number of girls in Dar-esSalaam are from Iringa and most of them left their home villages for the capital city in search of work as domestic servants, research has established. That being a case, the Iringa Regional Commissioner Major General James Luhanga has called on residents here to stop sending their children to work as domestic servants in Dar-es-Salaam and elsewhere or risk the possibility of receiving their daughters' bodies in coffins everyday because of HIV/AIDS. He told a gathering at Kilolo village in Kilolo District that Iringa Region is famous for producing housemaids for Dar-esSalaam, Morogoro and elsewhere, but every year, month and day we receive them in coffins or terminally ill due to HIV/AIDS (p.9).

\section{REFERENCES}

Farmer, P.E. 1992. AIDS and Accusation: Haiti and the Geography of Blame. Berkeley: University of California Press.

Hunter, S. and J. Williamson. 2000. Children on the Brink. Executive Summary United States Agency for International Development. Washington, D.C. USA.

Kwesigabo, G. 2001. "Trends of HIV Infection in the Kagera Region of Tanzania 1987-2000.” Umea University Medical 
Dissertations, New Series N0, 710, Umea, Sweden.

Lugalla, J.L.P. and J. Mbwambo. 1999. "Street Children and Street Life in Urban Tanzania: A Culture of Surviving and its Implication on Children's Health." International Journal of Urban and Regional Research 23(2):329-344.

Lugalla, J.L.P. et al. 1999. "The Social and Cultural Contexts of HIV/AIDS Transmission in Kagera Region, Tanzania." Journal of Asian and African Studies XXXIV (4):378-402.

Lugalla, J.L.P. and V. Barongo. 2000. "Profiles of Rural-Based Street and Orphaned Children in Ileje District, Tanzania." Unpublished Consultancy Report, UNICEF, Dar-Es-Salaam, Tanzania.

Lugalla, J.L.P. and C.G. Kibassa, eds. 2002. Poverty, AIDS and Street Children in East Africa. Lewiston, New York: The Edwin Mellen Press. USA.

Lugalla, J.L.P. and C.G. Kibassa. 2003. Urban Life and Street Children's Health: Children's Accounts of Urban Hardships and Violence in Tanzania. Berlin/Hamburg/Muenster: Lit Verlag.

National Bureau of Statistics of Tanzania and Oxford Policy Management Limited of United Kingdom. 2002. "Household Budget Survey (HBS) 2000/01." Final Report, Dar-es-Salaam, Tanzania.

Schoepf, Brooke, G. 2001. "International AIDS Research in Anthropology: Taking a Critical Perspective on the Crisis." Annual Review of Anthropology 30:335-361.

Schoepf, Brooke, G. 1996. "Health, Gender Relations and Poverty in the AIDS Era." In Courtyards, Markets, City Streets: Urban Women in Africa, edited by Kathleen Sheldon. Boulder, Colorado: Westview Press.

UNAIDS/WHO. 2001. “AIDS Epidemic Update.” Joint United Nations Programme on HIV/AIDS (UNAIDS) and World Health Organization (WHO). Geneva, Switzerland.

. 2002. "AIDS Epidemic Update." Joint United Nations Programme on HIV/AIDS (UNAIDS) and World Health Organization (WHO). Geneva, Switzerland.

UNAIDS/UNICEF/USAID 2002. "Children on the Brink.” A Joint 
Report on Orphan Estimates and Program Strategies. The TVT Associates, Washington, D.C. USA.

Watkins, K. 1996. "The Oxfam Poverty Report." Oxfam, United Kingdom and Ireland, Oxford, United Kingdom.

World Bank. 1998/99. World Development Report: Knowledge for Development. Oxford, U.K: Oxford University Press. 